\title{
La escuela: un parque de di-versiones para formar científicos
}

The amount of crime is determined not only by the rationality and preferences of would-be criminals, but also by the economic and social environment created by public policies, including expenditures on police, punishment for different crimes, and opportunities for employment, schooling, and training programs.

Gary Becker

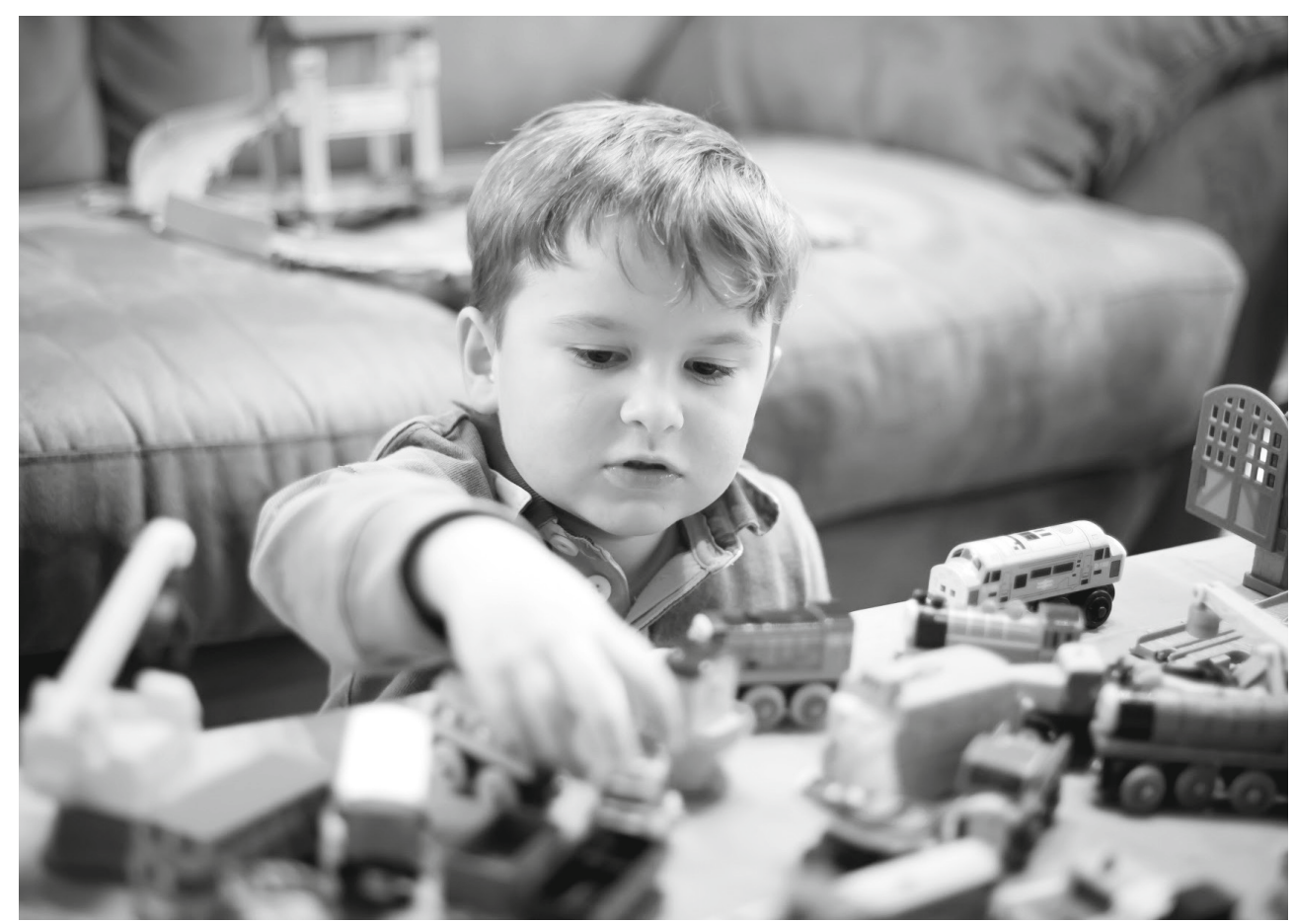

Las facultades de educación juegan dos papeles trascendentales, al menos, en la construcción de un ser humano moderno: de un lado, forman docentes con una perspectiva ilustrada, racional y científica; de otro lado, reconstruyen cada día desde el discurso pedagógico los caminos de los estudiantes en su formación como jóvenes ciudadanos, académicos y con el espíritu científico del mundo moderno de hoy.

Así, justamente, la escuela como academia tiene una gran responsabilidad en su conjunto para lidiar y proponer caminos ante los retos de la actual crisis, inédita en sus contextos y en sus posibles consecuencias. La escuela como institución debe asumir su mayoría de edad y proponer ya no meras opiniones, debe hacer acopio de su acervo y sumergirse en los rigores de la ciencia para contribuir a la reconstrucción biológica y social del ser humano de este siglo XXI, golpeado por sus propios desaciertos, tanto 
en su diálogo con los otros como con la naturaleza. Ya tiene la academia bastante quehacer con su indagación en los fenómenos de las disciplinas científicas en su designio por indagar los fenómenos de la naturaleza y de la matemática, y entonces debe asumir esa enorme responsabilidad que son las disciplinas sociales, con sus complejidades metodológicas, apoyadas por las disciplinas anteriormente mencionadas, con grandes propuestas rigurosamente construidas; aunque a veces con sonámbulas retóricas, con esa irresponsabilidad discursiva de las últimas décadas.

Y no debemos temer a la posibilidad de apostar desde las disciplinas sociales, en este caso, las disciplinas metadiscursivas sobre la educación (y sus vasos comunicantes de apoyo en sus formalizaciones y abstracciones desde las disciplinas naturales y formales), a la posibilidad de lograr discursos integradores con pretensiones universales...

toda la arquitectónica pragmática pierceana demuestra que lo universal es cognoscible sin tener que recurrir a lo Absoluto. El acople progresivo y relacional de los diversos sistemas del mundo va permitiendo detectar algunos invariantes entre los diferentes entramados; la confluencia evolutiva de la razón va decantando y depurando ciertas constantes. Son los "universales" que deben (y sólo pueden) detectarse en la "larga duración" braudeliana: sólo en la larga evolución de la cultura occidental pueden percibirse algunas permanencias dentro del cambio (...) La posibilidad real de acceder a lo universal desde entramados relacionales relativos, sin presuponer un inexistente Absoluto, es una de las más profundas enseñanzas del sistema pierceano (Zalamea, 2000, p. 180)ํ.

La ciencia es una y se manifiesta en disciplinas. Aunque la gigantesca dimensión del saber obligue a los especialistas a concentrar su mirada en su objeto particular, justamente la escuela como institución en su tejido debe construir los vasos comunicantes para no perder el sentido holístico de la vida sobre el planeta como un cometido del nosotros, con el aporte de cada uno como totalidad en sí misma, aunque consciente de que los sistemas construyen diálogos desde el tejido social y diálogos con la naturaleza, mediados por la palabra hecha discurso y las abstractas construcciones de la disciplinas formales; porque cada uno ha de asumir el deber de saberse individuo y comunidad a través de los pactos políticos en deliberación siempre actualizada, en un intercambio de cohesiones, de coexistencias, entre la parte y el todo, mediante una reconstrucción permanente del sentido y practicidad de la justicia en un mundo posible en la perspectiva de cada uno, aunque sujeto a una voluntad general siempre actualizada en ámbito de un debate público razonable.

La escuela como institución debe asumir, entonces, su capacidad para coordinar el discurso de la academia. Esto es, integrar los saberes desde sus esencias hacia los constructos complejos del conjunto de las disciplinas en las prioridades que el mundo reclama a cada uno como insumo en la perspectiva de una buena vida, desde cada uno en armonía con las comunidades superpuestas de sus contextos. Esta tarea implica un alto sentido pragmático, una bondad enorme con los encuentros y desencuentros

1 Zalamea, F. (2000). Ariel y Arisbe. Bogotá: Convenio Andrés Bello.

Revista PAPELES • ISSN 0123-0670 • Vol. 12(23) • pp. 8-10 • Enero-junio de 2020 
de visiones de mundo entre los sectores de la sociedad, en cuyo debate deberá primar el rigor de los argumentos y la voluntad política en aras de un mundo cada vez más equitativo.

Este siglo XXI ya traía muchos de los problemas económicos, ambientales, culturales, desnudados por la pandemia actual del coronavirus; esta crisis nos ha puesto en un escenario inédito en el que la escuela, en particular las facultades de educación, debe asumir estos retos, de modo urgente, con un sentido propositivo, riguroso en sus componentes e integrador en su apuesta política. La escuela, con sus expresiones, especialmente la ciencia, ha sido protagonista de la construcción moderna del ser humano. La escuela debe erigirse como el ágora de la reconstrucción de la sociedad moderna y sus contradicciones, para soñar con una polis bajo los umbrales de una modernidad siempre en diálogo hacia la justicia.

Enrique Ferrer-Corredor 